\title{
PRAZER E SOFRIMENTO ENTRE OS TRABALHADORES DE CALL CENTER
}

\author{
Carolina Scolari \\ Silvia Generali da Costa \\ Cláudio Mazzilli
}

\begin{abstract}
Resumo: Os conceitos de Taylor foram fundamentais para o desenvolvimento industrial no século XX. Ainda hoje, seus ensinamentos estão presentes em diversos ramos da economia, inclusive, no setor de call center. Call center é uma estrutura que visa ao atendimento de clientes com a utilização de um terminal de computador e de um aparelho telefônico. Esse setor sofreu grande expansão e, em 2006, foi responsável pela geração de 60 mil empregos diretos, tornando-se uma forma de contato e negócios atrativa para empresas do ramo público e privado. $O$ objetivo deste artigo foi analisar as vivências de prazer e sofrimento no trabalho entre os operadores de call centers. Foi realizada uma pesquisa qualitativa, estratégia de estudo de caso e método de análise dos dados, análise de conteúdo. Como resultados, foram elaboradas algumas categorias finais, entre elas as mediações no trabalho, analisada no presente artigo sob o referencial teórico da psicodinâmica do trabalho.
\end{abstract}

Palavras-chave: Qualidade de vida no trabalho. Satisfação no trabalho. Condições de trabalho. Call Center.

\section{Trabalho taylorista}

Taylor foi o iniciador da eficiência industrial. O método científico desenvolvido por Taylor visava substituir processos rotineiros por processos deduzidos de análise prévia. A tentativa de reduzir cada arte manual ou ofício a movimentos elementares 
que pudessem ser cronometrados, descritos e ensinados a qualquer pessoa foi tão bem-sucedida que, mesmo atualmente, apesar das críticas, se encontra presente em muitas das atividades desenvolvidas pelas empresas. Dejours (1992) afirma que o taylorismo é, ainda hoje, uma modalidade de organização do trabalho que continua ganhando terreno, especialmente no setor terciário.

Para Merlo (1999), o taylorismo provocou uma profunda modificação na organização do trabalho, ocasionando uma maior redução dos tempos mortos e a intensificação ao extremo da atividade do trabalhador. Para o autor, a principal fonte de agressão à saúde é a própria organização do trabalho, que detém certas características nocivas à saúde física e mental do trabalhador, tais como a apropriação de seu saber, que esvazia a tarefa de seu conteúdo, a repetitividade, a monotonia e a parcelarização do trabalho.

As repercussões do sistema de Taylor na saúde do corpo são assinaladas por Dejours (1992). Segundo o autor, uma nova tecnologia de submissão, de disciplina do corpo e de organização científica do trabalho gera exigências fisiológicas até então desconhecidas, especialmente exigências como tempo e ritmo de trabalho. As novas exigências fazem com que o corpo apareça como o principal ponto de impacto dos prejuízos do trabalho. O sistema Taylor neutraliza a atividade mental dos operários no momento em que separa radicalmente o trabalho intelectual do trabalho manual.

Taylor não estava focado nos aspectos humanos da organização, e sim na adaptação dos seres humanos à necessidade da organização mecânica. Apesar dos diversos estudos posteriores a esse autor sobre os aspectos humanos na organização, percebe-se que o surgimento de novos postos de trabalho, em diversos ramos de atividade, inclusive no setor de serviços, vem acompanhado de antigos conceitos, como é o caso do trabaIho nos call centers.

Segundo Zarifian (2001), os centros de chamadas telefônicas, call centers, são o símbolo contemporâneo da extensão do taylorismo. Por meio de atividades como as desenvolvidas pelos operadores dessas centrais, podemos perceber a presença do sistema taylorista nos dias atuais."Call center é o nome que se dá a uma estrutura organizacional que compreende postos de trabalho para atendimento ao cliente por meio da utilização de um terminal de computador e de um aparelho telefônico. Cada posto é chamado de Posição de Atendimento (PA)" (Vilela \& Assunção, 2004, p. 1069).

Para Silva (2004), o surgimento dos call centers ocorreu "na esteira do verdadeiro dogma da procura da qualidade total" (Ibidem, p. 11). Além disso, a venda direta ao consumidor por meios telemáticos tornou-se $o$ carro-chefe de grande número de empresas em todo o mundo e incorporou dezenas de milhares de trabalhadores nos últimos anos, em grandes estruturas de atendimento ao público baseadas no trabalho contínuo de teleatendentes em interface telefônico-informática (telemática).Tornou-se a principal forma de contato e negócios entre a grande maioria das empre- 
sas privadas e públicas e seus clientes e/ou usuários em ramos críticos da economia, como telefonia, serviços de utilidade pública, bancos, grandes indústrias, grande comércio, entre outros.

O sofrimento gerado por essa atividade não é um problema somente nacional. Segundo Kovács (2005), responsável pela realização de uma pesquisa em Portugal, os operadores de call center apresentam alta rotatividade, $97,4 \%$ possuem contrato temporário, $36,6 \%$ trabalham em tempo parcial, $22,4 \%$ estiveram desempregados nos últimos cinco anos. O conteúdo das tarefas é limitado e rotineiro, $45,9 \%$ deles receiam perder o emprego, 55,5\% têm vontade de mudar de emprego e 59,3\% desejam mudar de profissão.

\section{A dicotomia prazer e sofrimento no trabalho}

Abdoucheli e Jayet (1994) afirmam que psicopatologia do trabalho é a análise dinâmica dos processos psíquicos mobilizados pela confrontação do sujeito com a realidade do trabalho. É dinâmica, pois analisa os conflitos que surgem do encontro entre um sujeito, portador de uma história singular, e uma situação de trabalho cujas características são fixadas independentemente da vontade do sujeito. A psicopatologia de massa, em geral, é incapaz de emergir pelas pressões do trabalho, as reações de defesa são em função do passado, da história e da estrutura da personalidade de cada sujeito.

Estratégias defensivas surgem com o sofrimento e, por meio delas, os trabalhadores conseguem minimizar a percepção que têm das pressões organizacionais. De vítimas passivas, os trabalhadores passam a agentes ativos de um desafio. Os sujeitos, experimentando cada um por si um sofrimento único, seriam capazes de unir esforços para construir uma estratégia defensiva comum. A diferença entre o mecanismo de defesa individual e a estratégia coletiva é que o primeiro está interiorizado, persiste mesmo sem a presença física de outros, enquanto a segunda não se sustenta se não tiver um consenso, depende de fatores externos. A estratégia defensiva torna-se, muitas vezes, preciosa para os trabalhadores. O sofrimento é essencialmente o resultado do enfraquecimento da estratégia defensiva, e não consequência do trabalho. Essas estratégias funcionam também como sistema de seleção psicológica de trabalhadores, eliminando aqueles que se mostram reticentes (Abdoucheli \& Jayet, 1994).

Sendo inevitável, o desafio é transformar o sofrimento em criatividade, para contribuir beneficamente, pois, ao contrário, o mesmo funciona como mediador da desestabilização e fragilização da saúde. Em qualquer circunstância, o trabalhador nunca será considerado um indivíduo isolado, sempre tomará parte ativa nas relações de trabalho. A relação do trabalho aparece como uma relação intersubjetiva e uma relação social (Abdoucheli \& Jayet, 1994). 
Dejours expõe que o trabalho pode também ser fonte de prazer e mediador de saúde. Diferencia o sofrimento em dois tipos, que são o sofrimento criativo e o sofrimento patogênico. $O$ sofrimento criativo resulta em soluções originais que são favoráveis à produção e à saúde. No sofrimento patogênico, o indivíduo, em sua luta contra o sofrimento, pode chegar a soluções desfavoráveis à produção e à saúde. "O sofrimento é então definido como o espaço de luta que cobre o campo situado entre, de um lado, o bem-estar e, de outro, a doença mental ou a loucura. (Dejours, 1996, p. 153)

Para Dejours (2003), é do reconhecimento que depende o sentido do sofrimento. $\mathrm{O}$ sujeito pode utilizar-se desse reconhecimento para a construção de sua identidade.

Quando a qualidade do meu trabalho é reconhecida, também meus esforços, minhas angústias, minhas dúvidas, minhas decepções, meus desânimos adquirem sentido. Todo esse sofrimento, portanto, não foi em vão; não somente prestou uma contribuição à organização do trabalho, mas também fez de mim, em compensação, um sujeito diferente daquele que eu era antes do reconhecimento. (Dejours, 2003, p. 34)

Merlo et al. (2004) afirmam que o reconhecimento é condição indispensável no processo de mobilização subjetiva da inteligência e da personalidade no trabalho. Por esse motivo, desempenha um papel fundamental na possibilidade de se transformar o sofrimento em prazer.

As empresas podem obter vantagens com o sofrimento enfrentado pelos trabalhadores. $\mathrm{O}$ autor utiliza-se do caso das telefonistas para tratar da relação existente entre a "tensão nervosa" e a produtividade. As telefonistas que não têm como exteriorizar os seus sentimentos; quando sofrem alguma agressão, utilizam como saída o "trabalhar mais depressa", fato que faz com que aumentem a produtividade. “De um lado, temos a angústia como correia de transmissão da repressão e, de outro, a irritação e a tensão nervosa como meios de provocar um aumento de produção. $O$ trabalho não causa o sofrimento, é o sofrimento que produz o trabalho" (Dejours, 1992, p. 103)

O que é explorado pela organização do trabalho não é o sofrimento, em si mesmo, mas principalmente os mecanismos de defesa utilizados contra esse sofrimento. No caso das telefonistas, o sofrimento resulta da organização do trabalho "robotizante", que expulsa o desejo próprio do sujeito. A frustração e a agressividade resultantes, assim como a tensão e o nervosismo, são utilizadas especificamente para aumentar o ritmo de trabalho (Dejours, 1992).

Como não existe uma forma simples de o sujeito deter seu pensamento, muitos trabalhadores aceleram o ritmo de trabalho. Engajam-se na 
aceleração de maneira que ocupam todo o seu tempo de consciência com as pressões senso-motoras de sua atividade. Com uma sobrecarga perceptiva, o sujeito fecha a consciência ao pensamento organizado vindo do interior (Dejours, 1996).

Um dos fatores que exige a gerência do sofrimento em proveito da saúde e da produtividade é a diferença que ocorre entre a organização prescrita e a organização real do trabalho. Para ser operacional, a atividade prescrita necessita de reajustes. São diversas as maneiras que os trabalhadores utilizam para construir a organização real de trabalho. Quando os gestores adotam um estilo de direção excessivamente normativo e prescritivo, essa organização real do trabalho ocasiona grande sofrimento (Dejours, 1996).

Pagès et al. (1990) denominam como política de mediação da organização o acoplamento existente na organização de grandes incitações ao prazer e de exigências elevadas. Como elementos da organização que influenciam a formação da personalidade individual, esses autores citam, entre outros, o fato da organização ser uma máquina de prazer, ou seja, ofertar por múltiplas formas, o prazer de dominar e de ser dominado e a máquina da angústia por funcionar na base de exigências muito fortes, de um controle onipresente, da generalização, da ameaça e da retirada do prazer.

O sentimento dicotômico, antagônico e controverso, gerado pelo prazer e pelo sofrimento, parece ocasionar um equilíbrio de sentimentos na função.Segundo Dejours (1996), o equilíbrio é resultado de uma regulação que requer estratégias defensivas especiais elaboradas pelos próprios trabalhadores. Para Cunha (1999) o estudo dos mecanismos de defesa permite fundamentar estratégias defensivas para enfrentar o sofrimento no trabalho. Para a autora, tais estratégias podem ser definidas pelos mecanismos utilizados pelos trabalhadores para minimizar ou negar a realidade de trabalho que gera sofrimento.

Anna Freud (1982) afirma que Freud utilizou a palavra defesa, pela primeira vez em 1894, para descrever a luta do Ego contra idéias ou afetos dolorosos ou insuportáveis. A autora afirma que existem nove mecanismos de defesa que são: regressão, repressão, formação de reação, isolamento, anulação, projeção, introjeção, inversão contra o eu ${ }^{1}$, que pode ser definido em sua forma mais pura, como sinônimo do ego, e reversão. A autora acrescenta a esses métodos um décimo mecanismo considerado mais evoluído a uma pessoa classificada como neuroticamente normal, ou seja, a sublimação ou deslocamento de anseios instintivos.

Mazzilli e Agra (1998) afirmam que ações preventivas e postergadoras de conflito são tomadas pelas organizações, aliando as restrições dos novos métodos de trabalho a vantagens oferecidas ao indivíduo. Para os autores, as mediações se interpõem entre os objetivos da empresa e as percepções das coerções por parte dos indivíduos que poderiam conduzi-

1 Notas de Aula, Professor Cláudio Pinho Mazzilli (Grupos Organizacionais). 
los a reações de confronto. Para Lemos (2000), a organização utiliza-se de ações mediadoras que procuram justificar mudanças e comprometer a força de trabalho, atendendo a dupla necessidade de desenvolvimento e de controle da organização.

Para Mazzilli e Agra (1998) o binômio privilégio-restrição se transforma no binômio prazer-sofrimento. A angústia provocada pelos controles e pelas exigências dadas por metas desafiadoras é compensada pelo prazer de conquistar, prazer agressivo de dominação, de superar-se e de autodominar-se. Por esse meio, os indivíduos são integrados à organização mais do que por outros, pois no nível inconsciente, internalizam as restrições e os tipos de satisfações que ela oferece. Por meio de uma pesquisa qualitativa foram obtidos os resultados que se encontram descritos no decorrer do trabalho.

Para Macedo (2005), a pesquisa qualitativa não tem o objetivo de quantificar, mas sim de conhecer, de forma mais profunda, determinado grupo de pesquisa. Essa foi uma pesquisa do tipo descritiva. Segundo Gil (1999), são incluídas no grupo das pesquisas descritivas aquelas que têm por objetivo levantar as opiniões, as atitudes e as crenças de uma população. Quanto aos meios de investigação, este trabalho foi um estudo de caso.

Para Gil (1999), o estudo de caso é caracterizado pelo estudo profundo e exaustivo de um ou de poucos objetos, de maneira a permitir o seu conhecimento amplo e detalhado. Um estudo de caso é uma investigação empírica que investiga um fenômeno contemporâneo dentro de seu contexto da vida real, especialmente quando os limites entre o fenômeno e o contexto não estão claramente definidos (Yin, 2001, p. 32).

A coleta de dados foi realizada por entrevistas semi-estruturadas e pela análise de fontes documentais. A seleção da amostra ocorreu por conveniência, o que pode representar uma limitação presente na pesquisa. Os entrevistados foram indicados pela empresa e os supervisores podem ter escolhido os seus melhores operadores para participar. Muitas empresas fazem isso nas pesquisas das quais participam, visando melhorar a sua imagem organizacional. Participaram da pesquisa 16 operadores de call centers, 15 do sexo feminino e 1 do sexo masculino. As entrevistas semiestruturadas ocorreram no mês de janeiro de 2007. Para Gil (1999), a entrevista possibilita a obtenção de dados referentes aos mais diversos aspectos da vida social, além de permitir ao entrevistador captar a expressão corporal do entrevistado, bem como a tonalidade de voz e a ênfase nas respostas.

O método de análise dos dados qualitativos utilizado foi a análise de conteúdo. Moraes (1999) ressalta que a análise de conteúdo é uma metodologia de pesquisa utilizada para descrever e interpretar o conteúdo de toda a classe de documentos e textos. Essa análise ajuda a reinterpretar as mensagens e a atingir uma compreensão de seus significados em um nível além da leitura comum. Para Bardin (1977), a análise de conteúdo é 
um conjunto de instrumentos metodológicos em constante aperfeiçoamento e que se aplicam a discursos extremamente diversificados. Vergara (2006) ressalta que a análise de conteúdo é considerada uma técnica para o tratamento de dados que visa identificar o que está sendo dito sobre determinado tema.

Para Moraes (1999), a matéria-prima da análise de conteúdo pode ser qualquer material oriundo de comunicação verbal ou não-verbal, como cartazes, revistas, gravações, entrevistas, entre outros. No presente trabalho, as entrevistas foram gravadas e transcritas para servir de base a esse método.

\section{A empresa estudada}

A empresa estudada situa-se na grande Porto Alegre (RS) e tem como área de abrangência o mercado brasileiro. Iniciou suas atividades no ano 2000 com 30 postos de operação e 55 colaboradores. Atualmente, comporta 1.200 postos de atendimento e conta com 2.100 trabalhadores. Localiza-se em uma única cidade e, após a mudança de prédio, todos os postos de operação situam-se no mesmo endereço. A nova sede oferece praça de alimentação, área de conveniência, biblioteca, quadra poliesportiva e palco de eventos.

Os funcionários da empresa estudada têm um regime de trabalho de 6 horas diárias. Possuem dois turnos de trabalho, que compreendem um horário das $8 \mathrm{~h} 45 \mathrm{~min}$ às $14 \mathrm{~h} 45 \mathrm{~min}$ e das $15 \mathrm{~h}$ às $21 \mathrm{~h}$. A distribuição por sexo na empresa é de $85 \%$ de operadores do sexo feminino e $15 \%$ do sexo masculino. A porcentagem de operadores ativos, ou seja, que realizam ligações para o cliente, é de $98 \%$ e receptivos, ou seja, que recebem ligações, é de $2 \%$ na empresa.

A empresa possui 30 operadores por supervisor e em torno de 10 a 16 supervisores por gerente. Segundo Oliveira Júnior (2005), os call centers possuem estruturas extremamente achatadas. A relação entre gerentes, supervisores e atendentes tem a média de 1 gerente para cada 20 supervisores e, para cada supervisor, aproximadamente 20 atendentes. Na empresa estudada, o número de atendentes por supervisor é $50 \%$ maior, já o número de supervisores por gerente é menor.

Durante a visita, foram observados alguns fatores relevantes para o presente trabalho. Os banheiros são distintos para os operadores e para os supervisores, o que demonstra uma hierarquia constante. $O$ almoço é proporcionado para os supervisores e para os gerentes; os operadores têm direito a um lanche. Nos sábados, não há expediente para a área administrativa; o expediente nos postos de operação é normal. Obter uma promoção de operador para supervisor significa, inclusive, obter o direito de almoçar no refeitório e utilizar um banheiro distinto. 
Houve a possibilidade de observar, à distância, reuniões iniciais dos supervisores com as suas equipes de trabalho durante uma mudança de turno. Cada equipe de trabalho, após a reunião, possuía seu grito, música, entre outras coisas de "guerra". Uma das equipes cantava uma música do cantor Paulo Ricardo: "Se querer é poder, tem que ir até o final, se quiser vencer...,"de um programa que estava no ar na Rede Globo na época.

O barulho é realmente intenso. Durante as comemorações, aparecem diversos instrumentos que emitem ruídos sonoros. Além disso, há "pompons" que os operadores erguem automaticamente quando há um grito de guerra, mesmo que estejam em alguma ligação com clientes.

Os operadores falam muito rapidamente. Essa característica pode ser para que eles apresentem os seus produtos sem exigir muito tempo dos clientes.

\section{Análise dos dados}

A categoria denominada As mediações no trabalho foi elaborada a partir das categorias intermediárias Equipe de trabalho, Procedimentos específicos adotados na atividade, Mudanças físicas, emocionais e comportamentais da atividade, Os benefícios do diálogo entre os operadores e problemas das relações com os colegas.

Quadro 1. Derivação das categorias

\begin{tabular}{|c|c|c|c|c|c|}
\hline $\mathbf{N}^{\circ}$ & Categorias iniciais & $\mathbf{N}^{\circ}$ & $\begin{array}{c}\text { Categorias } \\
\text { intermediárias }\end{array}$ & $\mathbf{N}^{\circ}$ & $\begin{array}{l}\text { Categorias } \\
\text { finais }\end{array}$ \\
\hline 1 & Contato com pessoas & & & \multirow{7}{*}{ A. } & \multirow{7}{*}{$\begin{array}{l}\text { Fatores que geram } \\
\text { prazer no trabalho }\end{array}$} \\
\hline 2 & Ampliação das amizades & I. & $\begin{array}{l}\text { Relações } \\
\text { interpessoais no } \\
\text { trabalho }\end{array}$ & & \\
\hline 3 & $\begin{array}{l}\text { A forma de ingresso no } \\
\text { trabalho }\end{array}$ & \multirow[t]{5}{*}{ II. } & \multirow{5}{*}{$\begin{array}{l}\text { Benefícios do } \\
\text { trabalho }\end{array}$} & & \\
\hline 4 & $\begin{array}{l}\text { Maior identificação com a } \\
\text { forma de trabalho }\end{array}$ & & & & \\
\hline 5 & $\begin{array}{l}\text { Benefícios do vínculo } \\
\text { empregatício }\end{array}$ & & & & \\
\hline 6 & Reconhecimento profissional & & & & \\
\hline 7 & $\begin{array}{l}\text { Remuneração: é } \\
\text { responsabilidade de cada um }\end{array}$ & & & & \\
\hline
\end{tabular}




\begin{tabular}{|c|c|c|c|c|c|}
\hline 8 & $\begin{array}{l}\text { Tempo "livre" para o } \\
\text { atendimento: a cobrança é por } \\
\text { metas }\end{array}$ & \multirow[t]{5}{*}{ III. } & \multirow[t]{5}{*}{$\begin{array}{l}\text { A influência das } \\
\text { metas } \\
\text { no trabalho }\end{array}$} & \multirow{10}{*}{ B. } & \multirow{10}{*}{$\begin{array}{l}\text { Fatores que geram } \\
\text { sofrimento no } \\
\text { trabalho }\end{array}$} \\
\hline 9 & $\begin{array}{l}\text { A cobrança da empresa pelo } \\
\text { alcance das metas }\end{array}$ & & & & \\
\hline 10 & Cobrança pessoal por metas & & & & \\
\hline 11 & $\begin{array}{l}\text { Influência das metas no } \\
\text { ambiente familiar e influência } \\
\text { do ambiente familiar nas metas }\end{array}$ & & & & \\
\hline 12 & $\begin{array}{l}\text { Reações pessoais ao fracasso } \\
\text { no alcance das metas }\end{array}$ & & & & \\
\hline 13 & $\begin{array}{l}\text { Interferência negativa do } \\
\text { cliente no trabalho }\end{array}$ & \multirow[t]{3}{*}{ IV. } & \multirow[t]{3}{*}{$\begin{array}{l}\text { Interferências } \\
\text { externas ao trabalho }\end{array}$} & & \\
\hline 14 & $\begin{array}{l}\text { Reações à interferência } \\
\text { negativa do cliente no } \\
\text { trabalho:"Nada pessoal". }\end{array}$ & & & & \\
\hline 15 & Influência negativa da mídia & & & & \\
\hline 16 & $\begin{array}{l}\text { Interferência do barulho no } \\
\text { ambiente de trabalho }\end{array}$ & \multirow[t]{2}{*}{ V. } & \multirow{2}{*}{$\begin{array}{l}\text { Interferências } \\
\text { internas no trabalho } \\
\text { dos operadores }\end{array}$} & & \\
\hline 17 & $\begin{array}{l}\text { Reações ao barulho no } \\
\text { ambiente de trabalho: irritação } \\
\text { e nervosismo }\end{array}$ & & & & \\
\hline 18 & $\begin{array}{l}\text { A importância do trabalho em } \\
\text { equipe }\end{array}$ & \multirow[t]{8}{*}{ VI. } & \multirow[t]{8}{*}{$\begin{array}{l}\text { Equipe de trabalho: } \\
\text { apoio e conflito }\end{array}$} & \multirow{17}{*}{ C. } & \multirow{17}{*}{$\begin{array}{l}\text { As mediações no } \\
\text { trabalho }\end{array}$} \\
\hline 19 & O incentivo e o apoio do chefe & & & & \\
\hline 20 & $\begin{array}{l}\text { Cobrança de metas pela } \\
\text { equipe }\end{array}$ & & & & \\
\hline 21 & Competição & & & & \\
\hline 22 & $\begin{array}{l}\text { Incentivo ao diálogo pelos } \\
\text { supervisores }\end{array}$ & & & & \\
\hline 23 & $\begin{array}{l}\text { Diálogo: identificação e } \\
\text { tranquilização }\end{array}$ & & & & \\
\hline 24 & Imagem do colega & & & & \\
\hline 25 & Equipe heterogênea & & & & \\
\hline 26 & O script auxilia os iniciantes & \multirow[t]{5}{*}{ VII. } & \multirow{5}{*}{$\begin{array}{l}\text { Procedimentos } \\
\text { específicos adotados } \\
\text { na atividade: } \\
\text { facilidades e barreiras }\end{array}$} & & \\
\hline 27 & $\begin{array}{l}\text { Experiência no trabalho: as } \\
\text { adaptações do script }\end{array}$ & & & & \\
\hline 28 & $\begin{array}{l}\text { A interferência das gravações } \\
\text { telefônicas }\end{array}$ & & & & \\
\hline 29 & $\begin{array}{l}\text { Os carrapatos auxiliam o } \\
\text { colega }\end{array}$ & & & & \\
\hline 30 & $\begin{array}{l}\text { Auditoria: responsável pelo } \\
\text { fechamento da venda }\end{array}$ & & & & \\
\hline 31 & $\begin{array}{l}\text { Alterações positivas } \\
\text { provocadas pela atividade }\end{array}$ & \multirow[t]{4}{*}{ VIII. } & \multirow{4}{*}{$\begin{array}{l}\text { Mudanças físicas, } \\
\text { emocionais e } \\
\text { comportamentais da } \\
\text { atividade: aspectos } \\
\text { positivos e negativos }\end{array}$} & & \\
\hline 32 & $\begin{array}{l}\text { Sentimentos negativos } \\
\text { provocados pela atividade }\end{array}$ & & & & \\
\hline 33 & $\begin{array}{l}\text { Desgaste físico e mental da } \\
\text { atividade }\end{array}$ & & & & \\
\hline 34 & $\begin{array}{l}\text { Alterações físicas da atividade e } \\
\text { tentativa de auxílio da empresa }\end{array}$ & & & & \\
\hline
\end{tabular}


Na categoria As mediações no trabalho, percebe-se que os operadores estão constantemente em contato com fatores que geram prazer e, ao mesmo tempo, geram sofrimento em seu trabalho. Para Pagès et al. (1990) o indivíduo é profundamente ambivalente para com a organização que se torna objeto de identificação e de amor, fonte de prazer e, ao mesmo tempo, aquela que alimenta e fixa a angústia já que o indivíduo torna-se dependente dela para a sua existência material e para a integridade de sua identidade. Para o autor, prazer e angústia têm uma mesma origem, ou seja, no poder que tem a organização de levar o indivíduo a se identificar com ela.

Para Kets de Vries e Miller (1987) o mecanismo de identificação conduz a pessoa a pensar, sentir e agir da mesma forma que imagina o outro pensando, sentindo e agindo. Pagès et al. (1990) afirmam que o indivíduo constrói uma imagem do Ego grandioso, seu ideal do Ego, que encobre a imagem do ego pequeno e fraco e que se identifica com a organização. Segundo o autor, constrói-se uma organização imaginária que engloba as características da organização real com as quais o indivíduo se identificou. Para Anna Freud (1982) a identificação com o agressor só pode ser considerada normal enquanto o ego a empregar em seu conflito com a autoridade, isto é, em seus esforços para lidar com os objetivos de ansiedade. Para Pagès et al. (1990), o chefe é considerado o mediador da empresa a qual é constituída por um conjunto de tradições que se reproduz por meio das ordens e proibições do chefe.

Eu só olho pra minha supervisora, é que eu tô com a mesma supervisora já faz um ano e dois meses, então ela me conhece de longe, assim como eu conheço ela de longe. Então, eu só olho pra minha supervisora e ela diz assim: "Calma". Vamos ver, quem sabe um dia se resolve. Eu passei pra supervisora, ela colocou isso em reunião já algumas vezes em pauta.... Vamos ver se quem sabe um dia isso se resolve. (Entrevistado 3)

O supervisor influencia a sua equipe de trabalho. $\mathrm{O}$ incentivo e o apoio dele são muito gratificantes e necessários para um bom rendimento da equipe. $O$ apoio do chefe está presente em diversas situações, inclusive na dificuldade no início da atividade, e é fundamental para uma boa adaptação e transformação dos obstáculos em fatores positivos.

O que varia depende do dia do supervisor, ele que influencia, assim no teu estar na empresa. (Entrevistado 14).

Eu não estava mais acostumada a uma vida social, eu era mais dona de casa mesmo, era só casa, marido e filho, eu tinha esquecido que eu era útil para alguma coisa, não só para cuidar de casa e de criança. Eu cheguei aqui e fiquei, parece que eu não estava no meu ambiente, parece que eu não estava mais acostumada com isso, desde que 
eu saí da escola, só acostumada com familiares, amigos íntimos, mas chegar em algum lugar que não conhece ninguém, seguir as regras, por isso eu demorei um pouco para me adaptar, mas foi questão de dias, porque também ninguém é um bicho, tem que se adaptar.... Era mais por causa do sistema, a gente tinha que bater o cartão assim no horário certo, eu não estava adaptada com o sistema, mas daí eu peguei um supervisor muito legal, equipe muito gente fina, porque a gente sempre fica um pouco nervosa assim no início de emprego, mas o pessoal é bem legal, e também porque a gente não sabia direito, não pode ficar levantando toda hora, estas coisas assim, mas depois a gente vai se adaptando na boa. (Entrevistado 9).

O trabalho em equipe é outro benefício que gera prazer. A união da equipe também é fundamental em diversas situações e, no relato acima, percebemos que foi importante o apoio no ingresso e na adaptação da nova colega de trabalho. No entanto, a mesma equipe que apoia controla os colegas de trabalho durante qualquer pausa realizada, já que a obtenção de sucesso depende dos bons resultados da equipe. Segundo o relato de um entrevistado no estudo de Assunção, Silva e Lobato (2004), os operadores são pressionados pelos colegas de trabalho que, dentro de um raciocínio individualista, pressionam para a realização de horas extras. Ao mesmo tempo em que a equipe precisa atingir o objetivo e se une em torno disso, o ambiente é muito competitivo, pois é importante e gratificante obter um lugar de destaque na atividade. Para Garay (2005), ocorre a introjeção da dominação, ou seja, os trabalhadores passam a exigir de si mesmo o máximo de produtividade.

Para Cunha (1999) o que se sobrepõe ao equilíbrio psíquico é ser o trabalho lugar do prazer, da possibilidade do trabalhador consolidar-se enquanto sujeito, por meio do reforçamento da sua identidade pessoal e profissinal. A autora afirma que apesar das defesas gerarem consequências quase sempre negativas para a saúde mental no trabalho, elas são fundamentais na preservação do trabalhador frente ao sofrimento. Para a autora, o trabalho deve oferecer espaço para o reconhecimento e a valorização do trabalhador, o que permite o equilíbrio psíquico e o sofrimento e as defesas neste caso, permitem a regulação das relações sociais de trabalho.

As competições aparecem, já que só irão usufruir dos benefícios os melhores, ou seja, os que obtiverem mais vendas. A falta de possibilidade de sucesso para todos, nas mínimas coisas, como competição para folga para quem vende mais, é um fator desgastante. Para Mazzilli e Agra (1998) a política de reajustes internos de salários, bonificações, benefícios, participações nos lucros, participação nos resultados e promoções estão ligados às mediações econômicas.

O que mais me incomoda é quando está rolando alguma competição, por exemplo, a gente tem muita competição para folga, tipo os 15 primeiros do ranking folgam e os 15 últimos trabalham no sábado. Quando eu perco a folga, é fatal, quando eu não 
consegui vender para folgar, fico triste. Amanhã eu vou folgar,já tô bem. Mas quando não está rolando a venda, que eu tô fazendo o meu máximo, mas que eu não tô conseguindo vender, que o cliente fala que gostou do plano, que é bom, mas que não vai poder ficar, eu me irrito, porque tu sabe que a pessoa não tem dinheiro, mas você é obrigado para se sair bem na sua profissão, é obrigado a vender. Isso também me incomoda, quando eu não consigo, por exemplo, bater minha meta, não consigo entregar no final do dia a produção que eu tinha que entregar. (Entrevistado 9)

Segundo Vilela e Assunção (2004), as campanhas para estímulo de produtividade contemplam o atendente com brindes ou folgas e há estímulo à competitividade entre colegas, pois os programas de produtividade são baseados na individualização excessiva da produção. Segundo um dos entrevistados das autoras, "costuma ter umas gincanas para ver qual grupo de células produz mais. Eu já vi amizades acabarem por causa de prêmios bobos como uma camiseta".

Aqui na operação o que mais alegra as pessoas são brindes. Se tu ganha uma indicação, faz um contato com o cliente e vendeu. Tem alguém para indicar, uma irmã, uma amiga, um parente, um vizinho, daí tu indica, tu escreve na agenda de indicação e entra em contato com esta pessoa. Se a pessoa ficar, tu ganha um pirulito. Eu corro atrás da garrafinha da empresa X. Estes dias a minha supervisora falou que, se eu vendesse no Sábado, eu ia ganhar, daí eu vendi. Ontem eu não consegui, daí quando eu consigo, ela não tem disponível, é alguma coisa comigo, e quando eu não consigo ela tem. (Entrevistado 15)

Além disso, ao mesmo tempo em que o colega auxilia por meio do diálogo, já que ele promove uma identificação e tranquilização, promove o sofrimento pela imagem que é passada para a equipe de trabalho como a de uma equipe heterogênea. Para Kets de Vries e Miller (1987) o mecanismo de defesa denominado de projeção é identificado quando é atribuída a outra pessoa ou grupo uma atitude ou qualidade que possui, mas é rejeitada em si mesmo. Para Pagès et al. (1990) o sistema psicológico inconsciente passa por alguns estágios entre eles o da projeção. Para o autor, o indivíduo defende-se contra a sua angústia e sua agressividade, desenvolvendo um desejo agressivo de onipotência e projetando seu desejo na organização com a qual se identifica. Para Cunha (1999), para minimizar o sofrimento os trabalhadores desenvolvem mecanismos de defesa, que Ihes permitem submeter-se às condições mais adversas de trabalho, sem, no entanto, apresentar sintomas de loucura.

Dejours (1996) afirma que uma condição para a recondução do espaço da palavra é a transparência. Segundo o autor, a transparência é a visibilidade do trabalho efetuado pelo trabalhador, o acesso aberto aos outros de todas as seqüências de trabalho efetuado por eles, que às vezes ultrapassa a transparência, chegando a um "exibicionismo",ou seja, uma de- 
monstração pública da sua maneira de trabalhar, de forma que os colegas possam ver e conhecer cada companheiro. Para Mazzilli e Agra (1998) a mediação ideológica promove a democratização da palavra, dando lugar à variedade de interpretações individuais quanto a valores introduzidos.

Tu conversa, sabe quais as dificuldades deles, as suas, às vezes é algo assim que precisa conversar. (Entrevistado 8 )

Tem gente que fica insatisfeita porque começa reclamação, reclamação, reclamação, sabe? É pura insatisfação, uma pessoa que só reclama, tá insatisfeita, mas eu penso não tá satisfeita, não é obrigada a ficar, pede a conta, tuas coisinhas e tchau, tô indo embora, obrigada, eu sou assim, quero sair, saio da empresa numa situação boa, olha, não tô bem, se eu continuar não vou vender mais, não vai ser bom nem pra ti nem pra mim, então eu vou sair. (Entrevistado 16)

Abrahão, Assunção e Torres (2003) apresentam, em seu estudo, indicadores relacionados às estratégias de regulação e defesa. Segundo os autores, essas estratégias têm como função minimizar o desgaste, a fadiga e a tensão causados por situações de trabalho. Os indicadores que os autores citam, como estratégias operatórias (busca de informações na biblioteca e via telefone, troca de informações com colegas, transferências para ramais próximos quando aquele solicitado está desativado) e suporte social (relações interpessoais no ambiente de trabalho, consideradas como apoio para enfrentar as dificuldades do cotidiano), são considerados como possíveis fontes de prazer ou fuga do sofrimento no trabalho da telefonista.

Nos procedimentos específicos da atividade, facilidades e barreiras, podemos perceber que o sentimento em relação aos procedimentos adotados na atividade é ambíguo. Em relação ao script, percebe-se que, ao mesmo tempo em que os operadores o consideram um padrão para que a venda seja realizada com maior eficiência, considerando possuir certa liberdade de trabalho, consideram-no também ineficaz para atender a todo tipo de público. Além disso, a liberdade que consideram possuir em relação ao script vem acompanhada, em todos os depoimentos, da explicação de que não podem fugir das regras estipuladas pela empresa. Segundo Agra (1998), geralmente, indivíduos e grupos são integrados em torno de valores e crenças que reforçam os valores da organização. Para Lemos (2000), a motivação por criar reside na busca constante do ser humano por ordenações e por significados possibilitadores de sua orientação e comunicação em meio a outros seres humanos. "A potencialidade de criar passa a uma necessidade de realização desse potencial: o homem cria não apenas porque deseja ou gosta, mas principalmente porque precisa para crescer enquanto ser humano" (p. 27). Percebe-se que os operadores parecem vivenciar essa limitação à criatividade imposta pela empresa. $O$ processo criativo não é livre, consideram poder alterar a sua forma de falar, mas parecem 
perceber que isso é possível dentro de limites impostos pela organização. Há uma consciência da existência de informações obrigatórias de serem repassadas para o cliente e outras que são proibidas pela empresa, as quais só devem ser faladas caso haja um questionamento por parte da pessoa que se encontra do outro lado da linha. Mazzilli e Agra (1998) afirmam que o desejo dos indivíduos relativo ao controle de suas tarefas, posto em contradição com o estabelecimento de diretrizes e metas organizacionais, é mediado politicamente por técnicas de administração à distância ou de autonomia controlada.

Outra questão é o fato de o script não possuir tempo estipulado de ligação. Apesar de ser um fator benéfico, transfere para o operador a responsabilidade pelo número de ligações realizadas.

O script é básico, tu segue um padrão até pra ti vender melhor. Tu adapta aquilo que tu acha que é melhor pra ti vender... Tu tem liberdade, o que tu não pode fazer é sair do padrão, mas tu pode conversar normal.... não tem controle de tempo, claro que isso faz parte da tua própria ligação pra ti vender, até porque tu tem que ligar mais pra ter mais vendas, enfim. Mas se tu quiser ficar uma hora ali, pode ficar. (Entrevistado 2)

Se nós duas temos cartões, o que serve pra mim pode não servir pra ti. Então, por isso que eu não gosto muito de script. Eu gosto de falar o que me vem, assim, mas não saindo fora. (Entrevistado 4)

As gravações telefônicas também ocasionam um sentimento ambíguo nos operadores. Inicialmente, são descritas como um fator incômodo que preocupa os trabalhadores, mas, com o passar do tempo na empresa, acabam se transformando em uma forma de auxílio. No relato abaixo, percebe-se que o operador afirma que as gravações servem para auxiliar o serviço. Aparecem como uma forma de a empresa melhorar o atendimento prestado pelos operadores por meio de sugestões para a melhoria do seu desempenho.

o início, no caso as notas de monitoria, daí a gente ficava meio assim, mas depois fui vendo que não é, que não é assim, no começo a gente entra, já tá meio apavorado, ai meu Deus é gravada a ligação, depois tu vê assim, que no caso o pessoal tenta te ajudar, por isso gravam a ligação pra vê se você não tá fazendo algum erro, alguma coisa, se tá falando tudo direitinho e, se tu não tiver, eles te explicam o que tu tem que falar, o que tá certo, o que tá errado, as gravações são mesmo para a qualidade do atendimento ficar melhor. (Entrevistado 11)

Além disso, no relato, percebe-se que um dos operadores afirma utilizá-la como forma de proteção para não passar dados pessoais para o cliente, e a outra parece indecisa ao colocá-la como um fato incômodo. Pri- 
meiramente, afirma ficar nervosa por estar sendo avaliada e monitorada constantemente sobre o que fala e o que deixa de falar, mas em seguida diz não se importar.

Senhor, eu não posso falar nada da minha vida para o senhor, é gravado. (Entrevistado 15)

A gente fica meio nervoso porque a gente é avaliado, não só por vendas, mas por nota de monitoria também, que é a avaliação de qualidade. Então, às vezes eu não gosto porque é aquilo, né? Às vezes tu te passa, uma vez eu esqueci de falar que o seguro era por mês, aí a gente tem uma nota zerada. Então, é só nesse sentido que eu não gosto muito da ligação ser gravada, mas eu não me importo. (Entrevistado 3)

Os operadores podem estar utilizando um mecanismo de defesa para poder se inserir nesse sistema. Kets de Vries e Miller (1987) afirmam que o mecanismo de defesa denominado negação ocorre quando é negada a existência de um fato externo da realidade que gera conflito para o ego. Para Anna Freud (1982), o método de negação é empregado em situações em que é impossível evitar uma impressão dolorosa externa. Segundo a autora, esse método é baseado na fantasia de inversão dos fatos reais nos seus opostos.

Pela terceira categoria inicial,Auditoria: responsável pelo fechamento da venda, também percebemos que esse procedimento adotado pelo call center é fonte de prazer e sofrimento. Ao mesmo tempo em que se torna desgastante para o operador ter que passar para outra pessoa confirmar a venda, fato responsável pela perda desta em muitas situações, ter um baixo índice de vendas perdidas nesse procedimento gera certa satisfação. No relato abaixo, percebe-se que o entrevistado coloca que algumas vezes as vendas são perdidas nessa confirmação, mas logo após afirma que as vendas realizadas por ela são raras de cair, já que questiona sobre possíveis dúvidas e isso gera prazer por estar realizando o trabalho com competência e dedicação. Para Dejours (1996), quando o trabalhador resolve problemas que lhe são colocados e obtém um reconhecimento social do seu trabalho, é também o sujeito sofredor, mobilizador de seu pensamento, que recebe um reconhecimento subjetivo de sua capacidade para conjurar a angústia e dominar seu sofrimento. $O$ autor ressalta que o prazer obtido nesse processo é de curta duração e que o sofrimento ressurge, impelindo o sujeito para outras situações de trabalho, novas apostas organizacionais e novos desafios simbólicos.

O auditor finaliza a venda. No caso, eu ligo, falo tudo, passa para auditoria. Se o cliente diz que quer, eu passo pra auditoria e ela vai confirmar os dados do cliente, vai confirmar a aquisição do plano... Tem vezes que a gente perde ali na confirmação. Muitas vezes os clientes não entendem que têm que pagar, daí passa para auditoria, 
o cliente entendeu. Mas pelo menos as minhas vendas é raro de cair, porque eu ainda pergunto: "Os senhores têm alguma dúvida? (Entrevistado 1)

O quarto item que compõe a categoria intermediária Procedimentos específicos adotados na atividade: facilidades e barreiras, os "carrapatos" auxiliam o colega também é fonte de equilíbrio entre o prazer e o sofrimento no trabalho realizado pelos operadores do call center. Apesar da denominação pejorativa, "carrapato", as pessoas que são designadas para exercer tal atividade relatam sentir prazer. Esse prazer advém do fato de auxiliar os colegas a se adaptar ao novo trabalho e de ensiná-los a exercer a atividade. A possibilidade de avaliar o colega que está ingressando também pode ser fonte de prazer para o operador que está realizando essa atividade e mais uma fonte de desgaste para o novo integrante, que é monitorado em tempo integral durante esse período e logo após é avaliado pelo futuro colega de trabalho.

Multiplicadora é quando entram pessoas novas na empresa, a gente ensina elas. É "multiplicador", então a gente fica dois dias consecutivos com as pessoas novas, ensina a forma de falar com o cliente, a gente fica como carrapatos junto com o multiplicador pra fazer escuta, então, se tiver alguma coisa errada, a gente já corrige.... Logo que eles entram, a gente engata no discador e fica escutando tudo o que o cliente fala e o que eles falam também, a gente fica ajudando e, depois do sétimo dia que eles estão na operação, a gente volta de novo, aí a gente faz avaliação da pessoa, faz um parecer e entrega pra coordenação. (Entrevistado 5)

As mudanças físicas, emocionais e comportamentais proporcionadas pela atividade também parecem ser ocasionadoras de um equilíbrio, já que em alguns casos são positivas e em outros, negativas. A atividade provoca um sedentarismo físico, já que é realizada com a permanência dos operadores nas células de operação. Devido a pouca movimentação, pode gerar um aumento de peso, como foi verificado em alguns relatos.

Eu engordei por causa do horário. Não tenho horário pra comer regularmente, então eu chego em casa e vou almoçar às 4 h30min da tarde. (Entrevistado 4)

Além disso, há alguns relatos de controle da emoção em situações difíceis com clientes. O operador diz que deve ser educado, independentemente do que tiver escutado. Relata também alterações nervosas. O medo de dar uma resposta para o cliente parece também estar presente. Para Garay (2005) é na organização que os medos são manipulados: o medo de perder o emprego, de perder prestígio, de não ter chances na carreira etc., sendo que o controle do medo é extremamente desgastante, assim como acaba individualizando os trabalhadores. Para Cunha (2005) não mais o medo inerente a tarefa ou de não alcançar os níveis de desempenho dese- 
jados pela organização estão presentes, mas o medo da perda do emprego, desemprego que pode tornar-se estrutural deixando, portanto o indivíduo à margem do processo produtivo.

Conter a emoção porque tu não pode falar o que tu realmente quer falar, porque tu pode levar um xingão, de repente aquele dia o que tu mais queria ouvir era um muito obrigada, mas aí independente de como tu está, tu estando bem ou não, tu tem que manter uma estabilidade emocional, não pode estar falando, tu pode ouvir o que tu não quer, mas tu não pode falar o que tu quer, tem que sair na classe, né, normal. Muito obrigada, estas coisas assim, então tu acaba aprendendo de uma forma até te obriga a controlar mais, a ter noção, isso me ajudou porque eu era muito de dizer o que eu pensava e hoje não, hoje eu ouço mais, isso modificou bastante. (Entrevistado 16)

Em contrapartida, os operadores relatam que modificaram a sua forma de pensar sobre diversas situações, tornaram-se pessoas mais educadas, comunicativas e objetivas. No relato abaixo, percebemos que houve uma alteração na maneira de ser do entrevistado, alteração percebida pelo próprio operador. Segundo Dejours (1996), muitos sujeitos conseguem salvar seu equilíbrio e obter satisfações afetivas graças ao trabalho.

Antes eu era sempre bem na minha, caminhava na rua de cabeça baixa, agora, eu sou, como que eu vou dizer, mais espontânea, mais animada... fiquei bem mais espontânea e comunicativa também. (Entrevistado 9)

Eu fiquei mais calma, mais comunicativa, que eu não era muito antes, aprendi também a falar melhor com as pessoas, fiquei bem mais tranqüila. (Entrevistado 8)

O desgaste físico e mental é uma realidade do trabalho. Nas entrevistas, percebe-se que ele é maior quando ocorre a realização de um maior número de horas trabalhadas, ou seja, realizam-se horas extras. O sentimento em relação a esse desgaste também se torna ambíguo, já que as horas extras não são exigidas, pelo menos explicitamente, pela empresa. Para o operador, ao mesmo tempo em que são as responsáveis pelo maior cansaço, são também as responsáveis por uma remuneração melhor no final do mês.

Aqui a gente pode fazer hora extra para ter um salário melhor no final do mês. (Entrevistado 11) 


\section{Considerações sobre o estudo}

A hierarquia é muito presente na empresa, já que os "chefes" têm benefícios distintos dos operadores em diversos aspectos, tais como banheiros e refeições. No entanto, os operadores percebem isso como uma possibilidade de crescimento, e não como um fator negativo. A maioria dos supervisores passou pelos postos de atendimento, o que torna maior a identificação entre operador e supervisor, já que os supervisores conhecem bastante do trabalho dos seus subordinados. Além disso, os operadores acreditam no reconhecimento do trabalho realizado com dedicação e empenho e na possibilidade de ascensão profissional. Para eles, os que trabalham obterão uma promoção que só depende do tempo.

Como resultado da pesquisa, apareceram as mediações no trabalho proporcionando um equilíbrio entre o prazer e o sofrimento no trabalho dos operadores. A hipótese de que os trabalhadores estão encontrando um meio de administrar os problemas da organização do trabalho parece se concretizar. Ao mesmo tempo em que alguns fatores causam desgaste, outros proporcionam prazer.

A maioria dos fatores que surgiram como resultado da pesquisa gera sentimentos ambíguos em relação à atividade, entre eles os fatores responsáveis pela organização do trabalho e pelo relacionamento entre colegas e clientes na atividade. Pagès et al. (1990) afirmam que a organização apresenta-se para o indivíduo de forma extremamente gratificante e ameaçadora e, diante da ameaça e dos sentimentos de angústia e agressividade que ela provoca nos indivíduos, existe apenas a saída da identificação à organização e a aceitação das gratificações bem como do modelo de personalidade que os acompanham. Os fatores que geram prazer são fatores sociais que possibilitam o reconhecimento. Os fatores responsáveis pela geração de sentimentos negativos são, principalmente, referentes ao contexto e à estrutura do trabalho. Os operadores estão constantemente alternando sensações como, por exemplo, a felicidade na atenção de um cliente que é educado e chega a convidá-lo para visitá-lo em outro estado, a raiva, a frustração quando outro cliente é grosseiro e agressivo. Apesar de esses sentimentos ambíguos estarem presentes, os trabalhadores precisam administrá-los e é com as mediações do trabalho que isso se torna possível.

Uma sugestão para pesquisa futura é a comparação entre call center ativo e call center receptivo. A maioria dos trabalhadores da empresa estudada trabalha no call center ativo e as características do serviço no call center ativo diferem em alguns pontos do call center receptivo, tais como, tempo estipulado de ligação, tempo para inserção de dados no sistema, apego ao script, entre outros. 


\title{
Pleasure and pain among call center's workers
}

\begin{abstract}
The concepts of Taylor were essential for industrial development in the twentieth century. Even today, his teachings are present in various branches of the economy, including in the company's call center. Call center is a structure that aims at serving customers with the use of a computer terminal and a telephone. This sector has undergone major expansion and in 2006, was responsible for the generation of 60 thousand direct jobs becoming a contact form and attractive business for companies in public and private sector. The objective of this study was to analyze the experiences of pleasure and pain at work among the operators of call centers. We performed a qualitative research strategy, case study and method of data analysis, content analysis. As a result, some categories were drawn between them end the mediation at work, reviewed in this article under the theoretical framework of psychodynamic work.
\end{abstract}

Keywords: Quality of work life. Job satisfaction. Working conditions. Call Center.

\section{Le plaisir et la souffrance au travail chez les travailleurs de centre d'appel}

Resumè: Les notions de Taylor ont été essentielles pour le développement industriel du XXe siècle.Même aujourd'hui, ses enseignements sont présentes dans diverses branches de l'économie, y compris dans les call center de l'entreprise. Call Center est une structure qui vise à servir les clients avec I'utilisation d'un terminal d'ordinateur et un téléphone. Ce secteur a connu une expansion importante et, en 2006, a été responsable pour la production de 60 mille emplois directs devient une forme de contact et intéressant pour les entreprises dans le secteur public et privé. L'objectif de ce papier était d'analyser les expériences de plaisir et la souffrance au travail chez les exploitants de centres d'appels. Nous avons réalisé une stratégie de recherche qualitative, étude de cas et la méthode d'analyse des données, analyse de contenu. En conséquence, certaines dernières catégories ont été établies entre elles la médiation du travail, passé en revue dans cet article dans le cadre théorique des travaux psychodynamique.

Mots-clés: Qualité de vie au travail. La satisfaction au travail. Conditions de travail. Call Center. 


\section{Placer y sufrimiento entre los trabajadores de Call Center}

Resumen: Los conceptos de Taylor fueron fundamentales para el desarrollo industrial del siglo XX Todavia hoy, sus enseñanzas son presentes en muchos ramos de la economia, incluso, en la área de call center. Call center es una estructura que tiene como objetivo el atendimiento de los clientes con la utilización de ordenadores y de telélono. Este sector sufrió una grande expansión y , en 2006, fue responsable por generar más de 60 mil empleos directos convirtiendose en una forma de contactos y negócios atractiva para las empresas del ramo público y privado. El objetivo deste artículo fue analisar las experiências de Placer y Sufrimiento en el trabajo entre los operadores de call centers. Fue realizada una pesquisa cualitativa, estratégia de investigación del caso y método de análisis de los dados y análisis de contenido. Como resultado, se han elaborado algunas categorias finales entre ellas las mediaciones en el trabajo, analisada en este artículo bajo el marco teórico psicodinámica del trabajo.

Palavras clave: Calidad de vida en el trabajo. Satisfacción en el trabajo. Condiciones de trabajo. Call Center.

\section{Referências}

Abdoucheli, E., \& Jayet, C. (1994). Psicodinâmica do trabalho: contribuições da escola dejouriana à análise da relação prazer, sofrimento e trabalho. São Paulo: Atlas.

Abrahão, J., Assunção, A., \& Torres, C. (2003). Penosidade e estratégias de atenuação do risco: o caso das telefonistas de uma instituição pública. Estudos, Vida e Saúde, 30(1), 85-110.

Agra, C. D. (1998). As perspectivas do trabalho multifuncional em processos de reestruturação produtiva. Dissertação de Mestrado, Universidade Federal do Rio Grande do Sul, Porto Alegre.

Assunção, A., Silva, A., \& Lobato, S. (2004). O trabalho humano na sociedade das máquinas. Brasília, DF: Vergê Criação.

Cunha, E. G. (1999). Análise da dicotomia sofrimento e prazer em um programa de demissão voluntária. Dissertação de Mestrado, Universidade Federal do Rio Grande do Sul, Porto Alegre.

Bardin, L. (1977). Análise de conteúdo. Lisboa: Edições 70.

Dejours, C. (1992). A loucura do trabalho (5a ed.). São Paulo: Cortez-Oboré. 
Dejours, C. (1996). Uma nova visão do sofrimento humano nas organizações. In J. F. Chanlat (Org.), O indivíduo na organização: dimensões esquecidas (2a ed., vol. 1). São Paulo: Atlas.

Dejours, C. (2003). A banalização da injustiça social (5a ed.). Rio de Janeiro: FGV.

Freud, A. (1972). O ego e os mecanismos de defesa (2a ed.). Rio de Janeiro: Civilização Brasileira.

Garay, A. (2005). A busca da humanização do trabalho via prática de voluntariado empresarial. In Anais do $8^{\circ}$ Simpósio de Administração da Produção, Logística e Operações Internacionais. São Paulo: FGV-EAESP.

Gerencer, P. (1990). Vida e obra de Taylor. In F. W. Taylor, Princípios de administração científica (pp. 9-19). São Paulo: Atlas.

Gil, C. (1999). Métodos e técnicas de pesquisa social (5a ed.). São Paulo: Atlas.

Kets de Vries, M. F. R., \& Miller, D. (1987). The neurotic organization. San Francisco: Jossey-Bass.

Kovács, I. (2005). Flexibilidade do emprego no sector das tecnologias de informação e comunicação. Lisboa: Centro de Investigação em Sociologia Econômica e das Organizações, Departamento de Ciências Sociais, Secção de Sociologia.

Lemos, L. A. P. (2000). Análise do processo criativo no trabalho multifuncional: um estudo de caso. Dissertação de Mestrado, Escola de Administração, Universidade Federal do Rio Grande do Sul, Porto Alegre.

Macedo, M. M. C. (2005). Metodologia científica aplicada. Brasília, DF: Scala.

Mazzilli, C., \& Agra, C. (1998). O significado do trabalho multifuncional no processo de reestruturação produtiva da PETROBRÁS. In Anais do 22 Encontro Anual da ANPAD. Foz do Iguaçu, PR: ANPAD.

Merlo, A. (1999). A informática no Brasil: prazer e sofrimento no trabalho. Porto Alegre: Ed. da UFRGS.

Merlo, A. R. C., Vaz, M. A., Spode, C. B., Elbern, J. L. G., Karkow, A. R. M., \& Vieira, P. R. B. (2004). Trabalho, prazer, sofrimento e adoecimento em portadores de Lesões por Esforços Repetitivos. In A. Merlo (Org.), Saúde e trabalho no Rio Grande do Sul: realidade, pesquisa e intervenção (pp. 127-144). Porto Alegre: Ed. da UFRGS.

Moraes, R. (1999). Análise de conteúdo. Educação, 22(37), 7-32. 
Oliveira Júnior, M. M. (Coord.) (2005). Relatório da indústria de call centers no Brasil 2005. São Paulo: Programa de Pós-Graduação em Administração da PUC/SP e ABT.

Páges, M., Bobetti, M., Gaulejac, V., \& Descendre, D. (1990). O poder das organizações. São Paulo: Atlas.

Silva, A. M. (2004). A regulamentação das condições de trabalho no setor teleatendimento no Brasil: necessidades e desafios. Dissertação de Mestrado, Faculdade de Medicina, Universidade Federal de Minas Gerais, Belo horizonte.

Vergara, S. C. (2006). Métodos de pesquisa em Administração (2a ed.). São Paulo: Atlas.

Vilela, L. V. O., \& Assunção, A. A. (2004). Os mecanismos de controle da atividade no setor de teleatendimento e as queixas de cansaço e esgotamento dos trabalhadores. Cadernos de Saúde Pública, 20(4), 1069-1078.

Yin, R. K. (2001). Estudo de caso: planejamento e métodos. Porto Alegre: Bookman.

Zarifian, P. (2001). Comunicação e subjetividade nas organizações. In E. Davel \& S. C. Vergara (Orgs.), Gestão com pessoas e subjetividade (pp. 149-170). São Paulo: Atlas.

Carolina Scolari, Mestre pelo Programa de Pós-Graduação em Administração da Escola de Administração da Universidade Federal do Rio Grande do Sul. Rua Clemenciano Barnasque $\mathrm{n}^{\circ}$ 560. CEP: 91720-260, Teresópolis, Porto Alegre/RS. Endereço eletrônico:ccscolari@uol.com.br

Silvia Generali da Costa, Professora Pesquisadora Doutora, Programa de PósGraduação em Administração da Escola de Administração da Universidade Federal do Rio Grande do Sul. Rua Santa Tecla, 250/201. CEP: 91050-070, Jardim Lindóia, Porto Alegre, RS. Endereço eletrônico:sgcosta@ea.ufrgs.br

Cláudio Mazzilli, Professor Pesquisador Doutor, Programa de Pós-Graduação em Administração da Escola de Administração da Universidade Federal do Rio Grande do Sul. Rua Washington Luiz, 855, Centro. CEP 90010-460, Porto Alegre, RS. Endereço eletrônico:cpmazzilli@ea.ufrgs.br

Recebido em: 6/12/2008

Aceito em: 11/07/2009 